\title{
ЧИСЛО ДЕТЕЙ В СЕЛЬСКИХ ПОСЕЛЕНИЯХ ДАГЕСТАНА: СОПОСТАВЛЕНИЕ ИСТОЧНИКОВ ДАННЫХ
}

\author{
КОНСТАНТИН КАЗЕНИН
}

\begin{abstract}
В статье исследуется возможность использования данных учреждений, работающих на уровне муниципальных образований (администраций местного самоуправления, медицинских и образовательных учреждений), а также микроданных Всероссийской переписи населения 2010 г. для исследования рождаемости в населенных пунктах Республики Дагестан. Такое исследование представляется актуальным как в связи с известными проблемами с официальной демографической статистикой в Дагестане, так и в связи с большим разнообразием населенных пунктов Дагестана по уровню рождаемости, которое требует изучения и объяснения. В статье изложены результать исследования, в ходе которого в 2015 г. в десяти селах Дагестана были получены данные о численности детей 2000-2014 годов рождения от сельских администраций и медицинских учреждений, а по численности детей 2000-2007 годов рождения также от общеобразовательных школ. Эти данные сопоставляются между собой, а также (для 2000-2009 г2.), с микроданными Всероссийской переписи населения 2010 г. Показано, что эти источники обычно дают разную информацию по численности детей, но между ними сущуествуют регулярные, статистически значимые соотношения. На основании интервью, проведенных с работниками указанных учреждений в селах Дагестана, выдвигается гипотеза о том, почему между разными источниками данных о численности детей имеются обнаруженные расхождения. Обосновывается использование данных медицинских учреждений и икол как более надежных источников по абсолютному количеству детей разных годов рождения. Также сопоставляются данные сельских администраций и медицинских учреждений по числу женщин различных возрастов. На этой основе обсуждается возможность использования этих источников для вычисления коэффициентов рождаемости (общего коэффициента рождаемости, суммарного коэффициента рождаемости, коэффициента детности) для разных территорий Дагестана с ичелью сопоставления динамики репродуктивного поведения населения на этих территориях.
\end{abstract}

Ключевые слова: рождаемость, Северный Кавказ, муниципальная статистика, общий коэффициент рождаемости, суммарный коэффициент рождаемости.

\section{ВВЕДЕНИЕ}

Цель настоящей статьи - оценить возможности использования данных различных учреждений, функционирующих на муниципальном уровне, для исследования рождаемости в Дагестане. Вопрос об использовании таких данных представляется актуальным по следующим причинам.

КОНСТАНТИН ИГОРЕВИЧ КАЗЕНИН (kz@ranepa.ru), РОССИЙСКАЯ АКАДЕМИЯ НАРОДНОГО ХОЗЯЙСТВА И ГОСУДАРСТВЕННОЙ СЛУЖБЫ ПРИ ПРЕЗИДЕНТЕ РОССИЙСКОЙ ФЕДЕРАЦИИ, РОССИЯ.

СТАТЬЯ ОТРАЖАЕТ РЕЗУЛЬТАТЫ ИССЛЕДОВАНИЯ ПО НИР РАНХИГС 2016 Г. «ВЛИЯНИЕ СОЦИАЛЬНЫХ ИЗМЕНЕНИЙ НА РОЖДАЕМОСТЬ В РЕГИОНАХ СЕВЕРНОГО КАВКАЗА».

СТАТЬЯ ПОСТУПИЛА В РЕДАКЦИЮ В СЕНТЯБРЕ 2016 Г. 
Во-первых, в специальной литературе неоднократно указывалось на то, что ключевые процедуры сбора демографической информации, применяемые в масштабах страны (прежде всего, проведение переписей и ведение текущего учета населения), в ряде республик Северного Кавказа, включая Дагестан, сталкиваются со значительными трудностями [Андреев 2012; Богоявленский 2008, 2012], в силу чего для исследователядемографа в северокавказских регионах остро стоит вопрос об использовании дополнительных источников информации. Однако прежде, чем их использовать, необходимо оценить их достоверность.

Во-вторых, есть основания говорить о том, что в сегодняшнем Дагестане важно изучение различий в рождаемости, фиксируемых между небольшими территориями и даже отдельными населенными пунктами. Это обусловлено особенностями того этапа демографического развития, на котором сейчас находится Дагестан. Как было показано ранее [Казенин, Козлов 2016], данный регион демонстрирует количественные характеристики рождаемости, типичные для демографического перехода. Речь идет о снижении рождаемости до уровня простого воспроизводства (что соответствует значению суммарного коэффициента рождаемости немного выше 2,0). Такое снижение рождаемости произошло в Дагестане сравнительно недавно, в постсоветскую эпоху [Алиева 2007; Мудуев 2003]. Однако вопрос о том, в какой мере это снижение рождаемости сопровождалось социальными изменениями и, прежде всего, изменениями семейного уклада, типичными для демографического перехода, представляется открытым. Предварительные результаты полевых исследований в Дагестане показывают, что по «глубине» некоторых изменений, часто рассматриваемых в качестве неотъемлемой части демографического перехода - таких, как секуляризация семейной жизни, снижение роли «большой» семьи в пользу семьи нуклеарной и т.п. - территории республики демонстрируют заметное разнообразие [Kazenin, Kozlov 2016а]. Одновременно разные территории Дагестана имеют различия и по характеристикам рождаемости, на что также указывают предварительные данные полевых исследований. Например, в [Казенин, Козлов 2016] показано, что разница между некоторыми селами Дагестана по среднему возрасту матери при рождении первого ребенка в 2013-2014 гг. превышала два с половиной года. Некоторые данные официальной статистики позволяют предполагать, что между различными территориями Дагестана заметны и различия по уровню рождаемости. Так, общий коэффициент рождаемости, ежегодно подсчитываемый для районов Дагестана, в 2014 г. колебался в интервале 14,5-30,8 родившихся детей на 1000 жителей [Дагестанстат 2015: 47-60]. Хорошо известно, что общий коэффициент рождаемости как показатель, характеризующий репродуктивное поведение населения, весьма ненадежен даже в случае, если он высчитывается на основании абсолютно надежных данных демографического учета. Тем не менее такие "скачки" в значениях этого показателя по районам позволяют, по крайней мере, допустить возможность заметных территориальных различий по репродуктивной активности. Ожидания различий по рождаемости между разными территориями Дагестана подкрепляются разницей в их национальном составе. Как показано в [Богоявленский 2014], в поколении, достигшем на момент Всероссийской переписи населения 2010 г. 50-54 лет, у женщин разных народов Дагестана фиксировались заметные различия по итоговой рождаемости: у некоторых народов она составляла менее 2500 детей на 1000 женщин, а у некоторых - более 3000 детей. 
Итак, складывающаяся в Дагестане картина рождаемости делает этот регион весьма многообещающим для исследования социальных основ демографических трансформаций: если подтвердятся предварительные выводы о внутрирегиональных различиях по характеристикам семейного уклада, а также о внутрирегиональных различиях по рождаемости, то естественно будет задать вопрос о корреляции между этими различиями. Корреляции, которые окажутся значимыми, будут представлять существенный интерес для исследования условий первого демографического перехода. Отметим, что ранее для понимания этих условий много дало исследование территориального разнообразия протекания этого процесса внутри некоторых стран. В качестве примера можно привести исследование территориального разнообразия рождаемости в Индии: различия между ее регионами по уровню рождаемости и параллельные различия между ними по характеристикам организации семьи много обсуждались в литературе [Dyson, Moore 1983].

Однако для того, чтобы изучать территориальное разнообразие рождаемости в Дагестане, необходимо оценить имеющиеся источники по характеристикам рождаемости в муниципальных образованиях этой республики. Хотя исследование описанных выше вопросов вряд ли возможно иначе, как полевыми методами, для планирования такого исследования необходимы предварительные оценки (гипотезы) о различиях по рождаемости между разными территориями Дагестана. А для этого, в свою очередь, нужна оценка имеющихся источников по рождаемости в этом регионе в муниципальном разрезе. Проблемам такой оценки и посвящена настоящая статья.

В статье сопоставляются данные по рождаемости в населенных пунктах Дагестана, содержащиеся в опубликованных результатах Всероссийской переписи населения 2010 г., и данные трех типов учреждений, функционирующих данные на муниципальном уровне:

- администраций сельских поселений;

- медицинских учреждений, функционирующих в селах;

- сельских школ.

Ни один из этих источников не предлагает в "готовом" виде каких-либо показателей (коэффициентов), характеризующих рождаемость на уровне муниципальных образований. Однако все они содержат информацию о числе детей определенных годов рождения, проживающих в том сельском поселении, в котором работают эти учреждения. Поскольку количество детей служит числителем при вычислении большинства используемых в демографии коэффициентов рождаемости, оценить достоверность перечисленных источников информации именно по данному показателю представляется принципиально важным для оценки возможности использования этих источников в исследованиях рождаемости.

Мы сопоставили количество детей по всем указанным источникам в десяти населенных пунктах Дагестана (выбор населенных пунктов для исследования описывается в разделе 1). Между данными изучаемых источников обнаружились регулярные, статистически значимые различия, о причинах которых наше исследование также позволяет выдвинуть определенные предположения. На основе полученных результатов мы делаем выводы об относительной применимости данных четырех источников для оценки рождаемости на различных территориях Дагестана. 
Статья основана на исследовании, проведенном автором в селах Дагестана в 20152016 гг. В разделе 2 описывается способ проведения исследования и приводятся его базовые результаты, касающиеся различий между данными о количестве детей по годам рождения, полученными из вышеперечисленных источников, а также обсуждаются возможные причины различий между данными изучаемых источников. В разделе 3 отдельно рассматривается вопрос о возможности вычисления характеризующих рождаемость коэффициентов на основе этих данных.

\section{ЧЕТЫРЕ ИСТОЧНИКА ДАННЫХ О КОЛИЧЕСТВЕ ДЕТЕЙ В СЕЛЬСКИХ ПОСЕЛЕНИЯХ ДАГЕСТАНА}

Данные о численности населения, проживающего в некотором сельском поселении, по годам рождения в Дагестане можно получить, используя источники сельских администраций и находящихся в сельском поселении медицинских учреждений (это может быть больница, амбулатория или фельдшерско-акушерский пункт). Сведения о числе детей определенных возрастов можно также получить в сельских школах. Необходимо оговорить, что все три источника дают информацию именно о числе детей разных годов рождения, проживающих в селе на момент обращения к этим источникам, а не о родившихся в селе в разные годы. Следовательно, эта информация может искажать картину рождаемости в селе за предыдущие годы из-за детской смертности и миграций, однако «местных» источников, свободных от такого рода потенциальных искажений, к сожалению, нет.

Информация, которой располагают сельские администрации, основана на похозяйственных книгах. В последние 5-7 лет похозяйственные книги в большинстве сел Дагестана получили компьютерную версию. Это произошло благодаря внедрению информационной системы «ПАРУС - муниципальный учет». Данная система в том виде, в каком она используется в администрациях большинства сельских поселений Дагестана, включает примерно тот же состав рубрик, характеризующих каждое хозяйство в составе сельского поселения, что и «бумажные» похозяйственные книги, которые после внедрения системы «ПАРУС», как правило, не пополняются. Среди прочей информации система «ПАРУС» содержит данные о датах рождения всех жителей, зарегистрированных по адресам конкретных домохозяйств, и позволяет подсчитать общее количество жителей того или иного года рождения (с возможностью разбивки по полу), зарегистрированных в селе.

Медицинские учреждения, расположенные в сельских поселениях, отражают информацию о численности жителей разных возрастов в так называемых «паспортах участков», заполняемых участковыми врачами. Свои «паспорта» имеют как участки врачей-терапевтов, обслуживающих взрослое население, так и участки врачей-педиатров. Суммирование данных всех участковых паспортов по возрастам дает возможность определить общее количество жителей разных возрастов в селе. Какой-либо «синхронизации» данных, содержащихся в медицинских паспортах участков и в системе «ПАРУС», по-видимому, не осуществляется. Нами не было выявлено случаев, когда численность населения какого-либо года рождения в селе по данным этих двух источников совпадала бы полностью. Медицинские работники периодически пересматривают данные о численности населения на своих участках, учитывая выбывших и вновь прибывших, но 
отработанной системы, при которой, например, снятие человека с регистрации в селе автоматически вело бы к внесению изменений в медицинский паспорт участка, насколько мы могли судить, нет.

Наконец, информация по числу детей определенных годов рождения имеется в сельских школах. Эти сведения определяются наличным составом детей в школах. Отчетность школ не связана с отчетностью сельских администраций и медучреждений, поэтому данный источник можно считать независимым от двух других. Для сопоставления источников имеет смысл использовать «школьную» информацию по тем годам рождения, по которым предполагается полный охват детей школьным образованием. На 2015 г. таковыми можно считать 2001-2007 годы рождения. В паспортах общеобразовательных школ за 2014/2015 учебный год имеются данные об общей численности учащихся разных годов рождения, однако для того, чтобы сопоставлять эти данные с данным администраций и медицинских учреждений, необходимо знать, кто из учащихся данной школы проживает в других селах. Такая информация может быть дополнительно получена от школьных администраций ${ }^{1}$.

В ходе нашего исследования, проведенного в 2015-2016 гг., мы получили информацию о численности детей с 2000 до 2014 годов рождения от указанных источников в ходе поездок в десять сел Дагестана. Среди сел, включенных в исследование, пять относятся к равнинной зоне, три - к предгорной и два - к горной. Села существенно различаются между собой по общей численности населения: она колеблется в интервале 500-19000 человек. Два села многонациональны по составу, восемь других практически мононациональны (одна какая-либо национальность составляет в них более 95\%). В селах представлены следующие национальности: аварцы, даргинцы, кумыки, лакцы, чеченцы (совокупно эти национальности составляют более 70\% жителей Дагестана согласно Всероссийской переписи населения 2010 г.). Таким образом, рассматриваемое подмножество сел Дагестана включает села разных географических поясов, разной численности населения и разного национального состава.

В качестве четвертого используемого источника выступают данные Всероссийской переписи населения 2010 г. по числу детей разных годов рождения (с 2000 до 2009 г.) в селах, охваченных нашим исследованием. Информация о количестве жителей разных годов рождения по муниципальным образованиям и населенным пунктам содержится в микроданных переписи на сайте Росстата.

Статистические данные о жителях различных национальностей как в республике в целом, так и в отдельных муниципальных образованиях, неоднократно становились в Дагестане причиной политической напряженности. Это проявлялось, например, в канун

\footnotetext{
${ }^{1}$ Очевидно, что использование данных школ как источника информации о количестве детей в селе не имеет смысла в селах, где значительное количество учеников посещает школы других населенных пунктов (например, районных центров). В наше исследование, однако, такие села включены не были. Во всех исследуемых селах директора школ и сотрудники сельских администраций оценивали такую «образовательную миграцию» либо как вовсе не существующую, либо как ограниченную 2-3\% школьников села.
} 
Всероссийской переписи населения 2002 г. $^{2}$ По этой причине, излагая результаты исследования, мы не раскрываем названий сел и абсолютного количества их жителей по различным источникам. Эти данные имеются у автора, а приводятся лишь соотношения количества населения по разным источникам для изучаемых сел, а также различные коэффициенты, вычисляемые для сел на базе различных источников. Это представляется достаточным в контексте целей настоящей статьи.

Наибольшим охватом годов рождения характеризуются полученные нами данные медицинских учреждений. Эти данные по всем десяти селам содержат численность детей всех годов рождения с 2000 до 2014 г. Данные школ, разумеется, охватывали меньшее количество лет. В ряде сел эти данные удалось получить не по всем годам рождения, по которым ожидается полный охват детей школьным образованием. Данные сельской администрации в шести селах покрывали все годы рождения с 2000 до 2014, а в других селах имелись «лакуны» по отдельным годам. С учетом этого для всех сел в качестве базы сравнения выбираются данные медицинских учреждений, а другие данные представлены как проценты от числа детей по данным медиков. Микроданные Всероссийской переписи населения ограничены годом, предшествующим ее проведению (2009 г.). Также микроданные переписи отсутствуют по одному из десяти сел (село 7).

В таблицах 1-3 приводятся процентные соотношения между данными медицинских учреждений (принимаемыми за 100\%) и данными соответственно сельских администраций, школ и микроданных переписи.

На рисунке 1 для сел представлены средние за все годы рождения процентные соотношения числа детей по данным администрации, по данным школы и по данным Всероссийской переписи населения 2010 г. к числу детей по данным медицинского учреждения (подсчитаны как средние процентных соотношений для всех годов рождения, за которые по данному селу имеется информация от сопоставляемых источников; также приведены в таблицах 1-3).

Таблица 1. Отношение количества детей по данным сельских администраций к количеству детей по данным медицинских учреждений, по всем исследованным селам, по годам рождения детей, \%

\begin{tabular}{c|r|r|r|r|r|r|r|r}
\hline Село & 2000 & 2001 & 2002 & 2003 & 2004 & 2005 & 2006 & 2007 \\
\hline 1 & 102,3 & 104,5 & 105,8 & 113,3 & 101,9 & 110,6 & 102,8 & 104,5 \\
2 & & & & & & & & 130,0 \\
3 & 102,1 & 111,4 & 133,3 & 125,0 & 148,6 & 117,1 & 196,4 & 190,5 \\
4 & & & & & & 117,9 & 117,9 & 131,2 \\
5 & 115,2 & 111,4 & 103,8 & 119,8 & 123,3 & 110,8 & 123,4 & 107,7 \\
6 & & & & & 70,6 & 300,0 & 120,0 & 126,7 \\
7 & 42,9 & 84,6 & 62,5 & 80,0 & 142,9 & 150,0 & 71,4 & 100,0 \\
8 & 116,2 & 110,9 & 104,6 & 112,2 & 112,9 & 104,3 & 81,6 & 116,0 \\
9 & 85,7 & 140,0 & 88,9 & 133,3 & 100,0 & 130,0 & 140,0 & 113,3 \\
10 & 117,3 & 129,1 & 148,9 & 131,0 & 97,3 & 131,1 & 142,4 & 114,7 \\
Среднее за год & 97,4 & 113,1 & 106,9 & 116,4 & 112,2 & 141,3 & 121,8 & 123,5 \\
\hline
\end{tabular}

\footnotetext{
${ }^{2}$ Казенин К. (2002). Есть такие нации: перепись населения может изменить структуру Госсовета Дагестана // Время новостей. 26 сентября. URL:http://www.vremya.ru/print/27420.html (дата обращения 16.08.2016).
} 
Таблища 1 (продолжение)

\begin{tabular}{c|r|r|r|r|r|r|r|c}
\hline Село & 2008 & 2009 & 2010 & 2011 & 2012 & 2013 & 2014 & $\begin{array}{c}\text { Среднее соотношение } \\
\text { по селу }\end{array}$ \\
\hline 1 & 105,8 & 105,4 & 169,7 & 118,7 & 116,9 & 139,3 & 113,6 & 114,3 \\
2 & 115,6 & 139,3 & 150,0 & 111,5 & 132,3 & 131,3 & 135,3 & 130,6 \\
3 & 133,3 & 138,9 & 147,8 & 161,3 & 154,1 & 145,5 & 200,0 & 147,0 \\
4 & 108,8 & 126,2 & 119,9 & 121,5 & 116,4 & 134,1 & 127,9 & 122,2 \\
5 & 113,3 & 88,6 & 110,6 & 109,4 & 117,2 & 109,2 & 118,5 & 112,1 \\
6 & 133,3 & 115,0 & 140,0 & 96,0 & 123,3 & 100,0 & 112,9 & 130,7 \\
7 & 62,5 & 108,3 & 100,0 & 118,2 & 72,7 & 100,0 & 100,0 & 93,0 \\
8 & 111,4 & 110,4 & 114,9 & 114,3 & 112,7 & 115,3 & 129,0 & 111,1 \\
9 & 140,0 & 155,6 & 100,0 & 275,0 & 283,3 & 188,9 & 137,5 & 147,4 \\
10 & 169,8 & 162,1 & 125,0 & 135,8 & 128,2 & 142,9 & 116,0 & 132,8 \\
Среднее за год & 119,4 & 125,0 & 127,8 & 136,2 & 135,7 & 130,6 & 129,1 & \\
\hline
\end{tabular}

Таблица 2. Отношение количества детей по данным сельских школ к количеству детей по данным медицинских учреждений, по всем исследованным селам, по годам рождения детей, \%

\begin{tabular}{c|r|r|r|r|r|r|r|r|r}
\hline Село & 2000 & 2001 & 2002 & 2003 & 2004 & 2005 & 2006 & 2007 & $\begin{array}{c}\text { Среднее соотношение } \\
\text { по селу }\end{array}$ \\
\hline 1 & 102,3 & 122,7 & 71,8 & 83,7 & 95,3 & 88,3 & & & 94,0 \\
2 & 93,9 & 96,7 & 110,3 & 91,2 & 92,9 & 100,0 & 93,8 & 100,0 & 97,3 \\
3 & & & 100,0 & 100,0 & 85,7 & 97,1 & 135,7 & 119,0 & 106,3 \\
4 & 48,5 & 100,0 & 104,0 & 72,5 & 101,0 & 100,9 & 100,8 & 99,1 & 80,7 \\
5 & 59,1 & 92,9 & 88,5 & 87,7 & 98,8 & 93,2 & 98,4 & 98,9 & 79,7 \\
6 & & 76,5 & 111,1 & 76,9 & 100,0 & 116,7 & 70,0 & 86,7 & 91,1 \\
7 & & 100,0 & 112,5 & 120,0 & 128,6 & 125,0 & 100,0 & 100,0 & 109,9 \\
8 & & 98,0 & 98,6 & 95,7 & 100,7 & 88,1 & 74,3 & 95,8 & 93,0 \\
9 & 92,9 & 100,0 & 100,0 & 133,3 & 125,0 & 90,0 & 80,0 & 73,3 & 99,3 \\
10 & 55,8 & 85,5 & 93,6 & 84,5 & 90,7 & 75,4 & 93,2 & 95,6 & 84,2 \\
Среднее за год & 75,4 & 96,9 & 99,0 & 94,5 & 101,9 & 97,5 & 94,0 & 96,5 & \\
\hline
\end{tabular}

Таблица 3. Отношение количества детей по микроданным Всероссийской переписи населения 2010 г. к количеству детей по данным медицинских учреждений, по всем исследованным селам, по годам рождения детей, \%

\begin{tabular}{c|l|l|l|l|l|l|l|l|l|l|c}
\hline Село & 2000 & 2001 & 2002 & 2003 & 2004 & 2005 & 2006 & 2007 & 2008 & 2009 & $\begin{array}{c}\text { Среднее } \\
\text { соотношение } \\
\text { по селу }\end{array}$ \\
\hline 1 & 96,5 & 95,5 & 102,9 & 98,0 & 95,3 & 100,0 & 94,4 & 100,9 & 100,8 & 98,2 & 98,2 \\
2 & 109,1 & 126,7 & 134,5 & 138,2 & 128,6 & 157,1 & 218,8 & 170,0 & 140,0 & 146,4 & 146,9 \\
3 & 89,4 & 104,5 & 130,0 & 121,4 & 137,1 & 125,7 & 192,9 & 185,7 & 120,8 & 133,3 & 134,0 \\
4 & 123,2 & 130,9 & 118,7 & 108,3 & 126,0 & 126,8 & 125,2 & 116,5 & 109,6 & 120,6 & 120,5 \\
5 & 109,1 & 102,9 & 97,4 & 106,2 & 119,8 & 110,8 & 96,9 & 114,3 & 101,8 & 80,3 & 103,9 \\
6 & 173,3 & 135,3 & 188,9 & 184,6 & 111,8 & 300,0 & 180,0 & 160,0 & 173,3 & 140,0 & 174,7 \\
8 & 117,5 & 104,8 & 103,2 & 104,3 & 107,1 & 101,7 & 78,1 & 109,1 & 105,4 & 92,8 & 102,4 \\
9 & 142,9 & 100,0 & 100,0 & 133,3 & 100,0 & 110,0 & 100,0 & 80,0 & 90,0 & 122,2 & 107,8 \\
10 & 107,7 & 120,0 & 140,4 & 119,0 & 108,0 & 100,0 & 111,9 & 107,4 & 134,0 & 122,4 & 117,1 \\
Среднее за & 118,7 & 113,4 & 124,0 & 123,7 & 114,9 & 136,9 & 133,1 & 127,1 & 119,5 & 117,4 & \\
год & & & & & & & & & & & \\
\hline
\end{tabular}




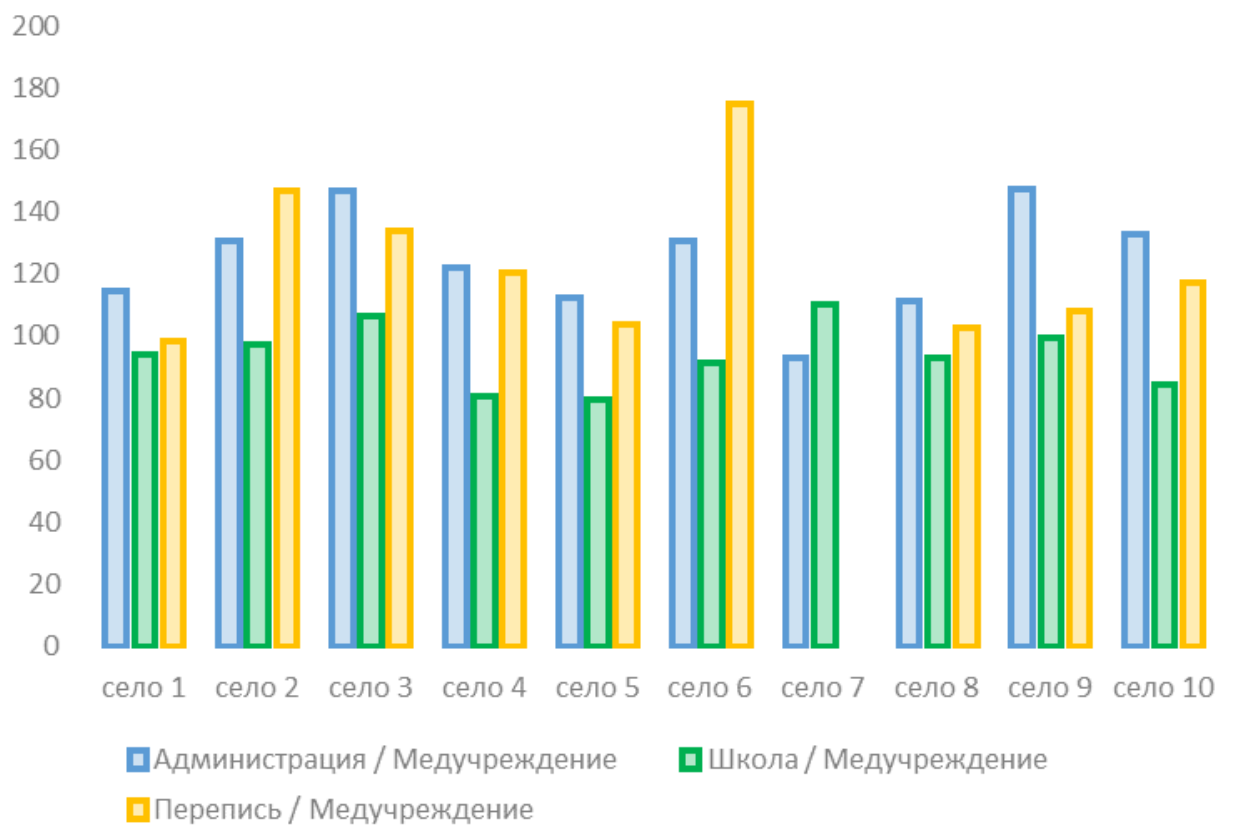

\section{Рисунок 1. Отношение числа детей по данным разных источников к их числу по данным медучреждений, все годы рождений, \%}

Сопоставим сначала три "местных" источника данных. На рисунке 1 можно видеть, что число детей по данным администрации регулярно (за исключением одного села из десяти) выше числа детей по данным медицинского учреждения. Число детей по данным общеобразовательной школы, наоборот, регулярно ниже числа детей по данным сельских медиков. В одном селе (село 7) нарушаются сразу две закономерности, еще в двух селах (селах 3 и 9) - по одной. Интересно отметить, что два села-«нарушителя» (села 7 и 9, и только они из всех десяти сел) расположены на землях отгонного животноводства крупном земельном массиве в равнинном Дагестане, где функционирование органов местного самоуправления и социальных учреждений имеет значительные отличия от других частей республики (подробнее об особенностях статистики населения на этих землях см. ниже).

Что касается микроданных переписи, то число детей по данным этого источника регулярно превышает число детей по данным школы и медицинского учреждения. При этом в некоторых селах число детей по микроданным переписи уступает их числу по данным сельской администрации, а в некоторых - превышает его.

На рисунке 2 показана динамика средних процентных соотношений числа детей по данным трех источников по годам рождения во всех исследуемых селах. Эти отношения вычисляются для каждого года как среднее процентное отношение количества детей по данным администрации (школы, переписи) к количеству детей по данным медучреждения во всех селах, для которых за данный год известно это отношение (отношения также приведены в таблицах 1-3). Видно, что «отрыв» данных администрации от данных медиков за все годы, кроме начала 2000-х, заметно больше, чем «отрыв» данных медиков от данных школ. Микроданные переписи за каждый год имеют среднее соотношение с данными медиков и школы, превышающее $100 \%$. В некоторые годы они уступают по этому показателю данным сельских администраций, в некоторые - превосходят их. 


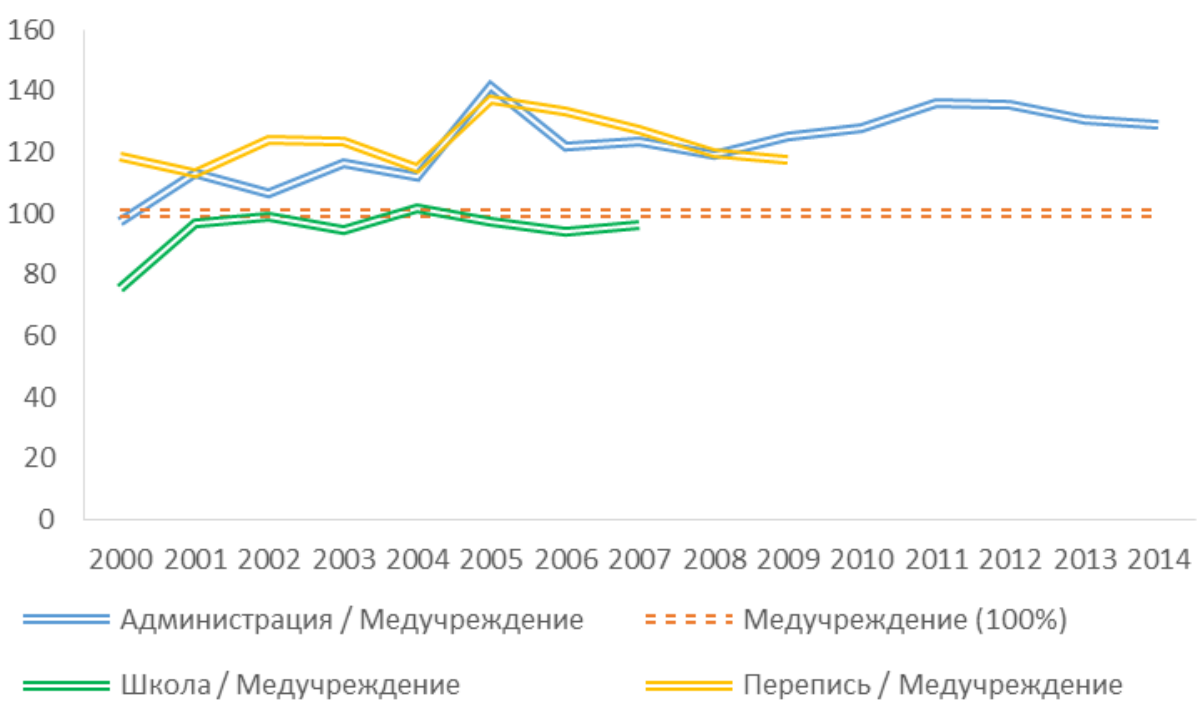

Рисунок 2. Отношение числа детей по данным разных источников к их числу по данным медучреждений, в среднем по всем 10 селам, \%

В таблице 4 содержатся среднее значение годовых процентных отношений (т.е. среднее значение процентных отношений, представленных на рисунке 2, за все годы), а также процентных отношений без учета года (подсчитаны как средние соотношения для сопоставляемых пар во всех селах за все годы).

Таблица 4. Отношение числа детей по данным разных источников к их числу по данным медучреждений, в среднем по всем 10 селам, \%

\begin{tabular}{l|c|c}
\hline & Среднее годовых соотношений & Среднее соотношение \\
\hline По данным сельской администрации & 122,41 & 123,68 \\
По данным сельской школы & 94,47 & 95,46 \\
По микроданным переписи & 122,87 & 122,87 \\
\hline
\end{tabular}

Рассмотрев имеющиеся процентные отношения «администрация/медики», «школа/медики» и «перепись/медики» как три выборки, мы можем определить для каждой из них стандартную ошибку среднего и границы доверительного интервала при желаемом уровне значимости (размер выборок, т.е. количество отношений, полученных для всех сел за все годы, позволяет считать распределение выборочных средних нормальным; при этом объемы выборок разные, поскольку, как мы видели выше, у каждого из трех соотношений разный набор сел, по которым оно доступно за тот или иной год). Как видно из таблицы 5 , при уровне значимости 95\% соотношение «администрация/медучреждение» не становится ниже $117 \%$, а соотношение «школа/медучреждение» остается ниже $100 \%$, хотя может быть очень близким к этой отметке. Соотношение «перепись/медучреждение» находится в доверительном интервале, очень близком к соотношению «администрация/медучреждение». Таким образом, обнаруженные на базе наших сел расхождения данных разных источников можно считать статистически значимыми. 


\section{Таблица 5. Доверительные интервалы для соотношений между данными разных источников}

\begin{tabular}{|c|c|c|c|}
\hline & $\begin{array}{l}\text { Администрация/ } \\
\text { медучреждение }\end{array}$ & $\begin{array}{c}\text { Школа/ } \\
\text { медучреждение }\end{array}$ & $\begin{array}{c}\text { Перепись/ } \\
\text { медучреждение }\end{array}$ \\
\hline $\begin{array}{l}\text { Среднее соотношение } \quad \text { (выборочное } \\
\text { среднее), } \%\end{array}$ & 123,68 & 95,46 & 122,87 \\
\hline $\mathrm{N}$ & 134 & 74 & 90 \\
\hline $\begin{array}{lrr}\text { Верхняя } & \text { граница } \\
\text { интервала }(p<0,05), \%\end{array}$ & 129,59 & 99,16 & 129,75 \\
\hline $\begin{array}{l}\text { Нижняя граница доверительного интервала } \\
(p<0,05), \%\end{array}$ & 117,77 & 91,71 & 115,99 \\
\hline
\end{tabular}

Доверительные интервалы, представленные в таблице 5, позволяют разбить исследуемые источники на две группы так, чтобы данные источников каждой группы по числу детей были статистически близки между собой. В первую группу попадут школы и медицинские учреждения. Несмотря на то, что число детей по данным школ регулярно несколько меньше, чем по данным медиков, верхняя граница доверительного интервала соотношения «школа/медики» находится между 99 и 100\%, т.е. почти касается той отметки, при которой число детей по двум источникам совпадает.

В другую группу, очевидно, входят данные сельских администраций и микроданные переписи. У обоих источников нижняя граница доверительного интервала отношения к числу детей по данным медиков превышает $115 \%$, т.е. эти два источника, как показывает элементарный статистический анализ, заметно превышают данные медиков и школ по числу детей. При этом верхние границы доверительных интервалов соотношений «администрация/медики» и «перепись/медики» почти совпадают, что позволяет говорить о большой статистической близости этих источников между собой, несмотря на имеющиеся расхождения между ним по конкретным годам и селам.

Чем может объясняться выявленное статистически значимое расхождение между данными администраций и микроданными переписи, с одной стороны, и данными медицинских учреждений и школ, с другой? Мы не имеем возможности определенно назвать причины этого расхождения, однако можем высказать некоторые предположения на основании интервью с работниками различных сельских учреждений, собранных в ходе нашего исследования.

Вероятная причина регулярно большего количества детей по данным сельских администраций по сравнению с данными медиков и школ заключается в том, что часть детей, зарегистрированных в селе вместе с родителями, фактически в нем не проживает: это семьи выходцев из села, которые могут жить либо в дагестанских городах, либо за пределами региона. Сельские жители, мигрирующие из села в город, с большой вероятностью сохраняют регулярные контакты с сельскими родственниками, периодически бывают в селе и находят постоянную регистрацию в нем более комфортной для себя (на «малой родине» легче получать необходимые документы и т.п.). Поскольку дети, проживающие в городе, не посещают в селе школу и медицинское учреждение, они с большой вероятностью не отражаются и в статистике этих учреждений. При этом семьи 
выходцев из села, проживающих в городе, могли лишь недавно туда мигрировать, а могли и сформироваться уже в городе. Поэтому мы не можем высказать обоснованных предположений о том, какая часть детей, «переучтенных» администрациями, родилась в селе и впоследствии уехала из него вместе с родителями, а какая часть родилась уже за пределами села.

Поскольку доверительные интервалы указывают на почти одинаковые границы отношения микроданных переписи и данных администраций к данным медиков, уместно предположить, что расхождение между переписной статистикой, с одной стороны, и статистикой медицинских учреждений и школ, с другой, имеет те же причины. Вместе с тем нельзя не заметить, что по конкретным селам и годам данные администраций и микроданные переписи почти никогда не демонстрируют полного числового совпадения или стабильной разности количества детей. Это показывает, что данные двух источников формировались самостоятельно, без прямой зависимости одного источника от другого. Видимо, речь можно вести не о технической зависимости одного источника от другого, а о сходных принципах учета населения при проведении в Дагестане переписи и при текущем учете населения сельскими администрациями.

Альтернативное объяснение регулярных расхождений между двумя группами источников могло бы состоять в том, что школы и медицинские учреждения недоучитывают детей, поскольку охватывают своими услугами не всех детей, реально проживающих в селе. Такое объяснение, однако, не подкрепляется имеющимися данными. В СМИ периодически появляются сообщения со ссылкой на правоохранительные органы о том, что часть детей школьного возраста в Дагестане без уважительных причин не обучается в школе ${ }^{3}$. Однако число таких детей, если верить официальным источникам, слишком мало, чтобы влиять на соотношение данных разных источников по селам: правоохранители сообщают о менее чем 300 детях, необоснованно не посещающих школу, по всей республике. Кроме того, следует заметить, что если бы в селах, включенных в наше исследование, на «школьные» данные заметно влияло непосещение школ живущими в селе детьми, то надо было бы ожидать, что число детей по данным школ наиболее существенно отставало бы от их числа по данным других источников, начиная с детей в возрасте 10-12 лет. Дело в том, что, по нашим полевым наблюдениям, в охваченных этим исследованием и других селах Дагестана запрет на посещение каких-либо общественных мест по религиозным соображениям родители чаще налагают на дочерей с возраста 10-12 лет (что касается непосещения школы из-за ранней беременности, то случаи деторождений в возрасте до 18 лет в исследованных селах носили единичный характер и не могли влиять на совокупные данные). В действительности же мы наблюдаем в исследованных селах заметное увеличение разрыва между «школьными» и «медицинскими» данными только для детей 2000 года рождения, т.е. тех, кому на момент исследования было 14-15 лет (см. рисунок 2). В целом имеющиеся данные не позволяют предложить правдоподобного

\footnotetext{
3 Прокуратура: более 200 детей в Дагестане не посещают школу по неуважительным причинам (2014) // Черновик. 18 декабря. URL: http://chernovik.net/content/lenta-novostey/prokuratura-bolee-200-detey-v-dagestanene-poseshchayut-shkoly-po (дата обращения 16.08.2016); Дроботов А. (2011). В Дагестане детей, не посещающих школу, будут отбирать у родителей // Комсомольская правда. 30 сентября. URL: http://www.kp.ru/daily/25762/2747750/ (дата обращения 16.08.2016).
} 
объяснения расхождений между источниками по числу детей в селах неполным охватом детей образовательными учреждениями. Что касается медицинских учреждений, то на возможный недоучет ими фактически проживающих в селе детей нет указаний ни в собранных нами интервью работников сельских учреждений, ни в сообщениях правоохранительных органов или СМИ. Отметим, что, в условиях подушевого финансирования, в таком недоучете были бы крайне не заинтересованы сами эти учреждения.

Итак, из возможных объяснений расхождения данных разных источников по числу детей в селах более обоснованным представляется объяснение, предполагающее учет в данных сельских администраций и в микроданных Всероссийской переписи населения 2010 г. детей из семей выходцев из села, фактически в нем не проживающих.

Отдельно остановимся теперь на «нестандартном» соотношении между данными различных источников в тех исследованных селах, которые находятся на землях отгонного животноводства (села 7 и 9). Особенность этих сел состоит в том, что они, находясь в границах равнинных районов, входят в состав горных районов. Отгонные земли в советское время предоставлялись в Дагестане горным колхозам и совхозам для выпаса скота в зимнее время. Тогда же на них стали стихийно возникать населенные пункты, в которых селились работники горных хозяйств. По данным Министерства сельского хозяйства и продовольствия Республики Дагестан, общее число населенных пунктов на землях отгонного животноводства составляет примерно 200. Общую численность населения на отгонных землях в Бабаюртовском районе, где находится 110 из этих 200 сел, республиканский Минсельхоз на 2012 г. оценивал в 26 тыс. человек ${ }^{4}$. Официальных данных о численности населения на всех отгонных землях на текущий момент нет. В настоящее время часть населенных пунктов, расположенных на отгонных землях, не имеет какоголибо официального статуса, а часть является отдельными муниципальными образованиями горных районов (от которых эти населенные пункты в территориальном отношении значительно удалены) ${ }^{5}$. Оба включенных в наше исследование «отгонных» села относятся ко второму типу. Наши интервью с сотрудниками администраций таких сел показали, что там распространена ситуация, когда жители, постоянно проживающие в селе, зарегистрированы на своей исторической родине, в одном из сельских поселений в горах. Одной из причин этого является нестабильный режим регистрации жителей на землях отгонного животноводства. Большинство жилых домов там не имеют легального статуса, так как расположены на землях сельскохозяйственного назначения, в связи с чем в настоящее время у сельских администраций нет и права предоставлять жителям постоянную регистрацию в этих домах. По свидетельству сотрудников местных администраций, в ситуации запрета на регистрацию они в ряде случаев все же продолжают вносить информацию о вновь прибывающих в село в систему «ПАРУС», хотя не всегда регулярно. В такой ситуации в данных администраций возможен не только учет фактически не проживающего населения (наблюдаемый и в прочих селах), но и недоучет фактически

\footnotetext{
${ }^{4}$ В Дагестане предлагают легализовать стихийные поселки на сельхозземлях (2012) // Memo.ru. 16 aвгуста. URL: http://www.memo.ru/d/131407.html_(дата обращения 13.12.2016).

${ }^{5}$ Подробнее см. [Казенин 2015a, 2015b].
} 
проживающего. Поэтому и ожидаемо, что в «отгонных» селах нарушается выявленная нами закономерность, состоящая в регулярно большем числе детей по данным администрации по сравнению с данными медиков и школ.

Подведем итог. Среди четырех рассмотренных нами источников данных о числе детей в селах Дагестана нет ни одной пары источников, данные которых полностью бы совпадали или регулярно отличались друг от друга на одну и ту же величину. Все четыре источника отражают разные системы учета. Однако данные администраций и микроданные переписи регулярно превосходят данные школ и медицинских учреждений о числе детей. Мы видели, что такое соотношение статистически значимо. Рассматривая возможные его причины, мы нашли некоторые основания предполагать, что в данных администраций и микроданных переписи могут быть отражены дети из семей, фактически не проживающих в селе. По этой причине при оценке количества детей различных годов рождения в селах Дагестана данные школ и медицинских учреждений представляются более надежными. Это не распространяется на населенные пункты, расположенные на землях отгонного животноводства, где ряд особых, действующих только там, факторов делает соотношение числа детей по разным источникам менее предсказуемым.

\section{ВЫЧИСЛЕНИЕ КОЭФФИЦИЕНТОВ РОЖДАЕМОСТИ НА ОСНОВЕ ДАННЫХ РАЗНЫХ ИСТОЧНИКОВ}

В предыдущем разделе мы рассмотрели возможность использования разных источников о числе детей в селах при исследовании рождаемости в Дагестане. Если какой-либо источник признан надежным (выше мы оценили в качестве более надежных источников данные медицинских учреждений и школ), то он может быть использован для сопоставления рождаемости в данном селе и в других населенных пунктах (во введении мы объяснили, почему эта задача весьма актуальна для Дагестана).

Хорошо известно, однако, что для сопоставления рождаемости в разных сообществах требуются не абсолютные данные о родившихся детях, а различные коэффициенты рождаемости, для вычисления которых, помимо числа родившихся детей, необходимо знать численность определенных групп взрослого женского населения (при вычислении коэффициента суммарной рождаемости, коэффициента детности и др.) или численность всего населения (при вычислении общего коэффициента рождаемости).

Для подсчета коэффициентов мы можем использовать данные только двух «местных» источников: сельской администрации и медицинского учреждения, - поскольку школы не обладают данными о возрастной структуре взрослого населения (в том числе женщин) $)^{6}$. Рассмотрим сначала возможность вычисления таких коэффициентов, где в качестве знаменателя выступает число женщин определенных поколений. К сожалению, мы имели возможность сопоставить данные администраций и медицинских учреждений по количеству женщин разных годов рождения не во всех исследуемых селах. Данные по

\footnotetext{
6 Возможность вычисления коэффициентов на основе микроданных переписи мы в этом разделе не рассматриваем в силу их большой статистической близости с данными администраций.
} 
количеству женщин по годам рождения из двух источников мы получили только для трех сел. Как показывают рисунки 3-5, в трех этих селах, существенно различающихся по количеству населения, число женщин по данным двух источников соотносится по-разному, причем имеются также серьезные колебания этого соотношения за разные годы для одного и того же села (села немного отличаются границами временных промежутков, за которые удалось получить данные из обоих источников; рисунки 3-5).

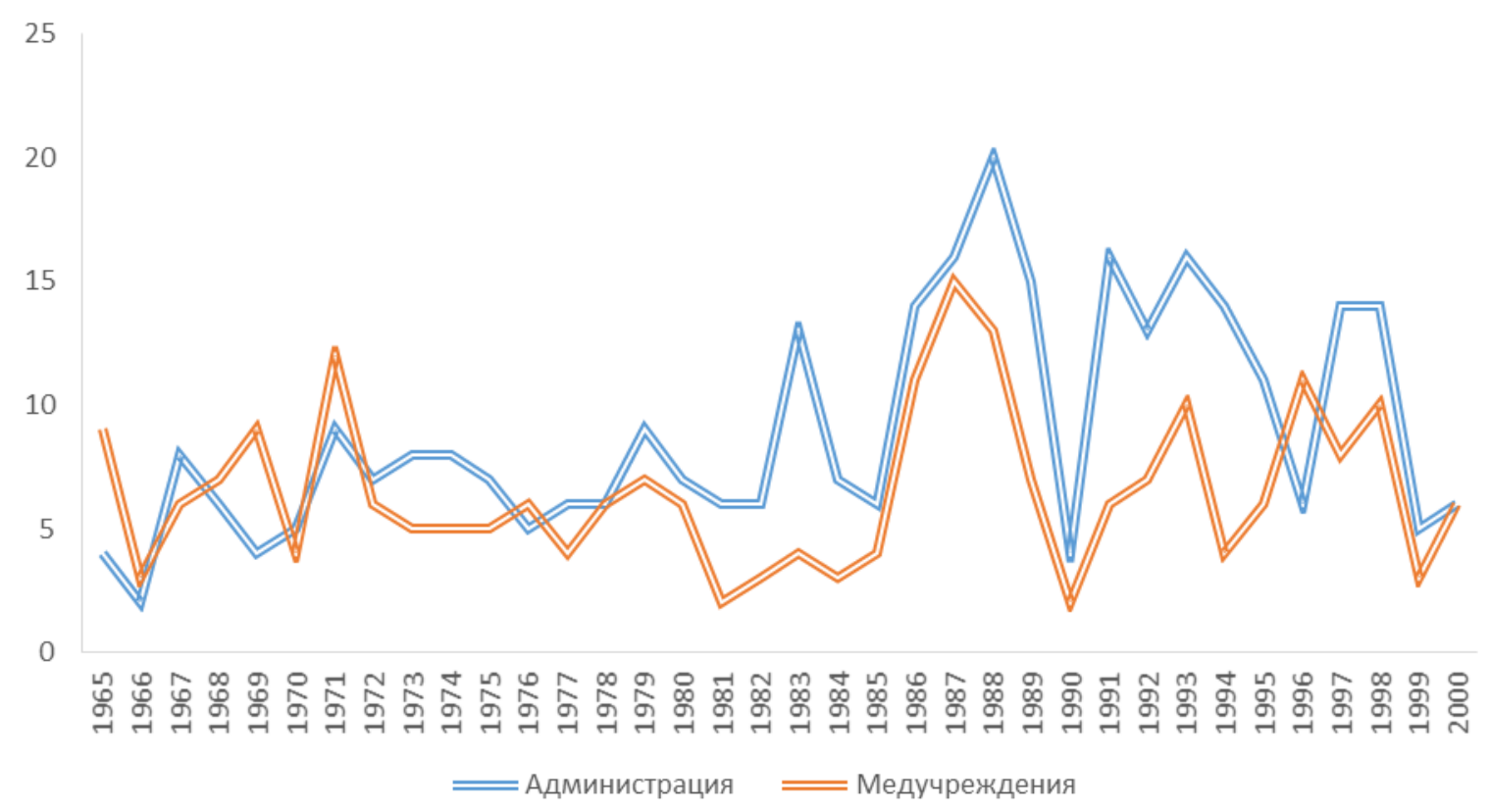

Рисунок 3. Число женщин по годам рождения: село 6

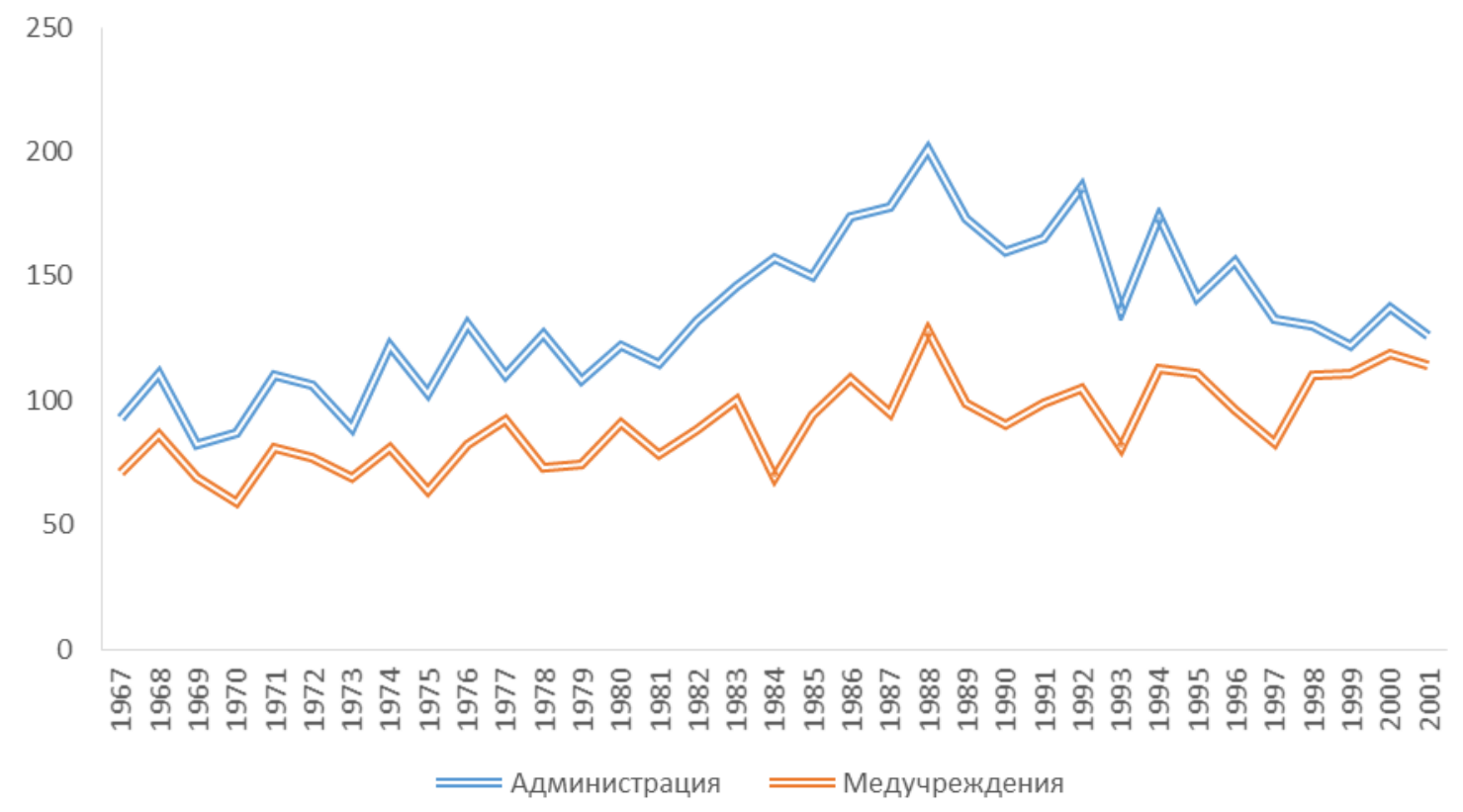

Рисунок 4. Число женщин по годам рождения: село 8 


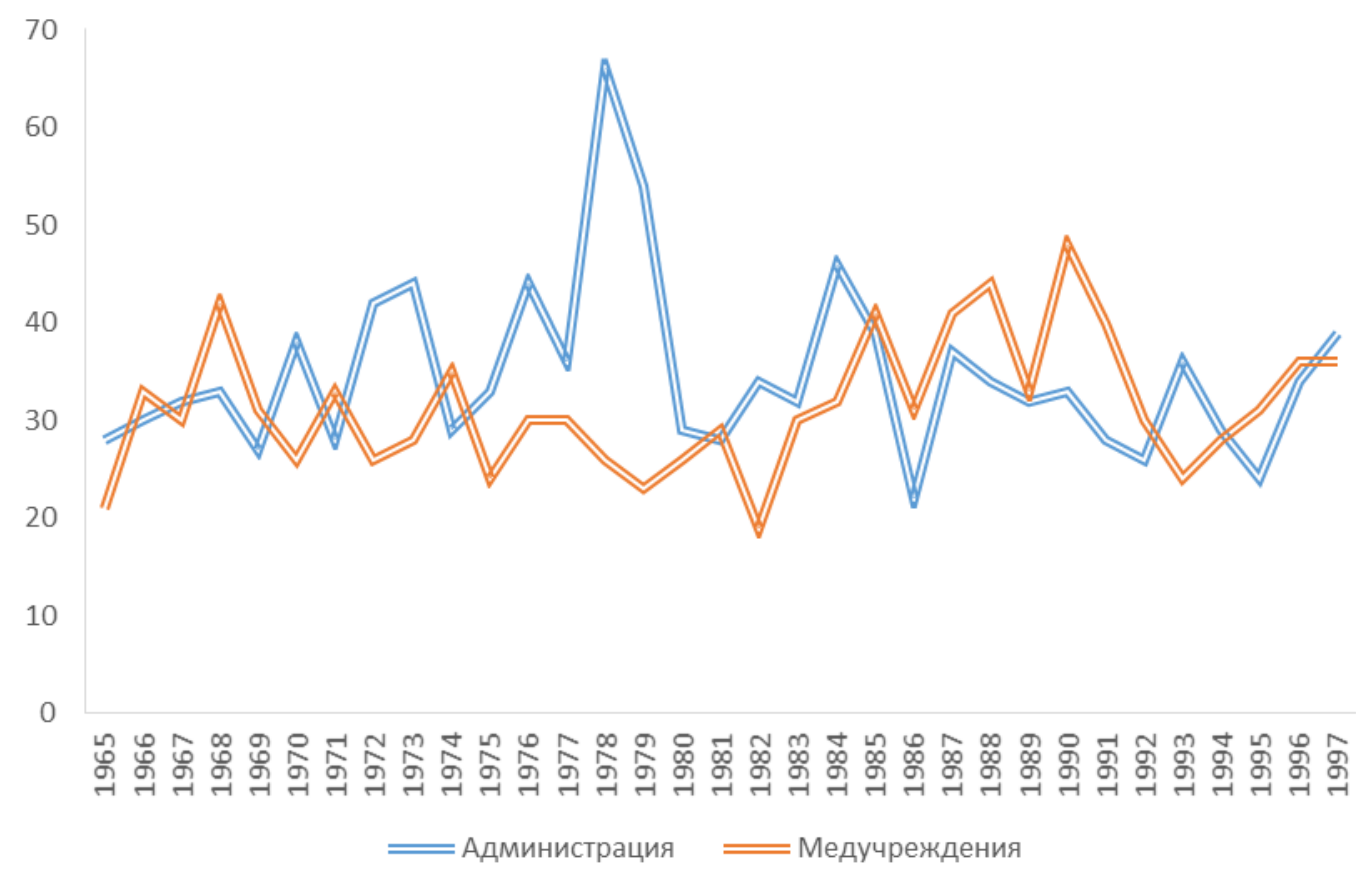

\section{Рисунок 5. Число женщин по годам рождения: село 10}

Нерегулярность соотношения числа женщин, определяющих знаменатели коэффициентов рождаемости, по двум источникам заставляет предположить, что нерегулярным будет и соотношение самих этих коэффициентов, вычисленных по данным этих источников. Эта нерегулярность будет ожидаемой даже при выявленном нами статистически предсказуемом соотношении данных по количеству детей, т.е. соотношении числителей.

Данные о числе женщин по поколениям требуются для вычисления коэффициента суммарной рождаемости и возрастных коэффициентов рождаемости. Для коэффициента детности достаточно знать лишь общее число женщин детородного возраста (15-49 лет), которое выполняет там роль знаменателя при числителе - количестве детей 0-4 лет. Данные по общему количеству женщин детородного возраста на момент, близкий к времени исследования, от двух источников нам удалось также получить в трех селах. Коэффициенты в определенных точках времени (незначительно отличавшихся от села к селу) и используемые для их вычисления данные представлены в таблице 6. Как видно из таблицы 6, число женщин детородного возраста по данным администрации во всех селах выше, чем по данным медиков. Однако «разброс» значений по разным селам разный. Как следствие, имея коэффициенты детности, подсчитанные для разных сел по разным источникам, мы не сможем на основании одних этих коэффициентов судить, связаны ли различия между ними с разной численностью детей, женщин или обеих этих групп населения по двум источникам. Поэтому сопоставление рождаемости по таким коэффициентам также затруднено. 
Таблица 6. Коэффициенты детности по отдельным селам

\begin{tabular}{|c|c|c|c|c|c|c|c|c|}
\hline \multirow[t]{2}{*}{ Село } & \multicolumn{3}{|c|}{ Женщины детородного возраста } & \multicolumn{3}{|c|}{ Дети 0-4 лет } & \multicolumn{2}{|c|}{ Коэффициент детности } \\
\hline & 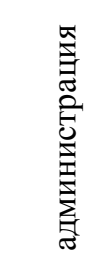 & 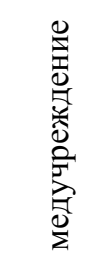 & 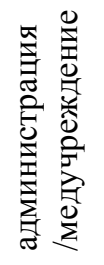 & 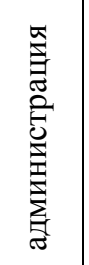 & 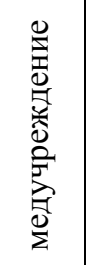 & 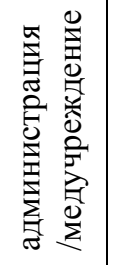 & 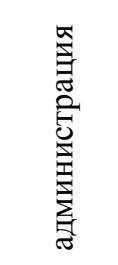 & 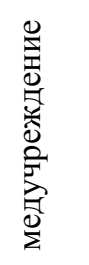 \\
\hline Село 5 & 1679 & 1172 & 1,43 & 676 & 598 & 1,13 & 0,40 & 0,51 \\
\hline Село 6 & 317 & 229 & 1,38 & 175 & 128 & 1,36 & 0,55 & 0,56 \\
\hline Село 8 & 4693 & 3841 & 1,22 & 2065 & 1892 & 1,09 & 0,44 & 0,49 \\
\hline
\end{tabular}

Итак, наши наблюдения не дают возможности утверждать, что данные «местных» источников позволяют вычислять коэффициент суммарной рождаемости или коэффициент детности, которые в свою очередь могли бы стать надежной основой для сопоставления рождаемости по селам. Для «грубой» оценки уровня рождаемости может, как известно, применяться также общий коэффициент рождаемости (далее ОКР), т.е. отношение родившихся в течение года к среднему общему числу жителей на этот год. Мы имели возможность вычислить этот коэффициент на основании данных двух источников для семи сел на 2014 г. ${ }^{7}$ Как видно из таблицы 7, ОКР, посчитанный на основе данных администрации, регулярно выше, чем ОКР, посчитанный по медицинским данным; исключение составляет только село 7 (напомним, что оно расположено на землях отгонного животноводства, где, как мы видели, соотношение данных из разных источников во многом отличается от наблюдаемого в других селах). При этом, после исключения из рассмотрения села 7, для любой пары сел, если ОКР, вычисленный по данным администрации, у одного села больше, чем у другого, то у этого же села больше и ОКР, вычисленный по данным медицинского учреждения (рисунок 6). Иными словами, исследуемые села одинаково ранжируются по ОКР, подсчитанному по данным сельской администрации, и по ОКР, подсчитанному по данным медучреждения. Такое «согласие» данных двух независимых источников позволяет использовать ОКР для сопоставления рождаемости по разным селам. То, что такого «согласия» источников не наблюдается, например, для коэффициента детности (таблица 6), может быть объяснено тем, что у этого коэффициента меньший, чем у ОКР, знаменатель, вследствие чего возможные различия знаменателей при подсчете коэффициента по разным источникам на значения ОКР влияют меньше, чем на значения коэффициента детности.

Итак, исходя из наших наблюдений, можно утверждать, что предварительное сопоставление уровней рождаемости в разных населенных пунктах Дагестана возможно на основе ОКР, подсчитанного по данным медучреждений. Надежность такой оценки подкрепляется, во-первых, описанными выше преимуществами данных медучреждений по

\footnotetext{
${ }^{7}$ ОКР подсчитан для большего числа сел, чем коэффициент детности, поскольку для ОКР достаточно было получить общую численность населения села, тогда как данные о числе женщин определенных возрастов оказались доступными в меньшем числе сел. Не подсчитаны ОКР для сел 4, 9 и 10, где не удалось получить сведения об общей численность населения по данным медицинского учреждения.
} 
количеству детей, а во-вторых, ожидаемым на основе наших наблюдений сходством в ранжировании сел по ОКР, подсчитанным по разным показателям. При этом, разумеется, необходимо помнить, что причина различий между разными территориями по ОКР может быть связана не только с репродуктивным поведением, но и с возрастной структурой женского населения. Практика показала, что получить полные данные о ней из местных источников часто весьма затруднительно. Тем не менее при отборе населенных пунктов для дальнейшего углубленного исследования различий в рождаемости и их причин такой способ оценки соотношения рождаемости представляется достаточным.

Таблица 7. Общие коэффициенты рождаемости в некоторых из исследованных сел по данным администраций и медучреждений

\begin{tabular}{|c|c|c|c|c|c|c|}
\hline \multirow[t]{2}{*}{ Село } & \multicolumn{2}{|c|}{$\begin{array}{l}\text { Общая численность населения } \\
\text { (соотношение источников), \% }\end{array}$} & \multicolumn{2}{|c|}{$\begin{array}{l}\text { Число детей, родившихся в } 2014 \text { г. } \\
\text { (соотношение источников), \% }\end{array}$} & \multicolumn{2}{|c|}{$\begin{array}{l}\text { Общий коэффициент } \\
\text { рождаемости, \%о }\end{array}$} \\
\hline & 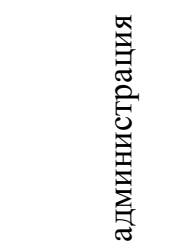 & 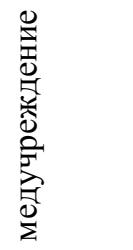 & 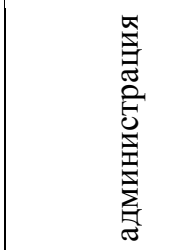 & 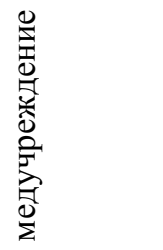 & 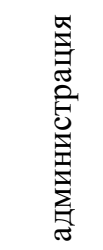 & 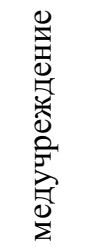 \\
\hline Село 1 & 101,0 & 100 & 113,6 & 100 & 30,56 & 27,18 \\
\hline Село 6 & 111,2 & 100 & 112,9 & 100 & 27,07 & 26,65 \\
\hline Село 5 & 117,0 & 100 & 118,5 & 100 & 26,50 & 26,17 \\
\hline Село 8 & 105,9 & 100 & 129,0 & 100 & 26,31 & 21,61 \\
\hline Село 2 & 123,1 & 100 & 135,3 & 100 & 18,24 & 16,60 \\
\hline Село 3 & 136,5 & 100 & 200,0 & 100 & 16,50 & 11,26 \\
\hline Село 7 & 127,1 & 100 & 100,0 & 100 & 20,61 & 26,20 \\
\hline
\end{tabular}

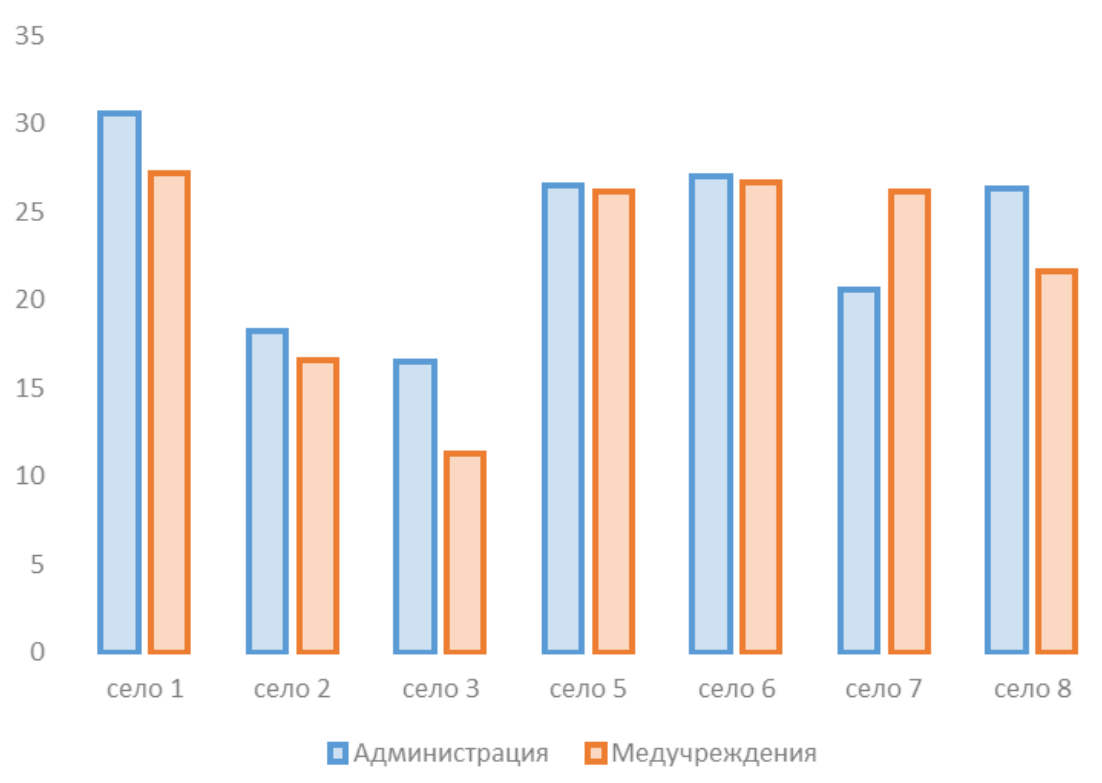

Рисунок 6. Общие коэффициенты рождаемости, рассчитанные на основе данных из разных источников, \%о 


\section{Выводы}

Мы видели, что данные разных источников об абсолютном числе детей по годам рождения в дагестанских селах находятся в достаточно регулярном, статистически значимом соотношении друг с другом. Полученные результаты позволили нам предположить, что данные медицинских учреждений и школ являются более адекватным источником для оценки числа детей в селе.

Заметно более ограничены возможности использования источников, доступных в дагестанских селах, для вычисления коэффициентов рождаемости. Мы видели, что данные этих источников о числе в селе женщин разных годов рождения соотносятся друг с другом нерегулярно, что не позволяет ожидать регулярности и в соотношении коэффициентов. Вместе с тем простые коэффициенты рождаемости, посчитанные на основе данных медиков, могут быть использованы для предварительного сопоставления рождаемости в разных селах.

Наш общий вывод состоит в том, что для изучения внутрирегионального разнообразия рождаемости - задачи, весьма актуальной для такого демографически «нестандартного» субъекта РФ, как Дагестан, - исследователь может пользоваться данными учреждений, работающих в сельских поселениях. При всех известных сложностях с учетом населения в Дагестане данные разных источников находятся в предсказуемых соотношениях и могут служить инструментом для выявления территориальных контрастов по рождаемости, подлежащих уточнению и объяснению в ходе дальнейшего исследования.

\section{БЛАГОДАРНОСТИ}

Автор благодарит С.В. Захарова и В.А. Козлова за ценные консультации в ходе подготовки статьи. За все оставшиеся недочеты ответственность несет только автор.

\section{ЛИТЕРАТУРА}

Алиева В.Ф. (2007). Демографические процессы в современном Дагестане. М.: Наука. $325 \mathrm{c}$.

Андреев Е.М. (2012). О точности результатов российских переписей населения и степени доверия к разным источникам информации // Вопросы статистики. 11: 21-35.

Богоявленский Д.Д. (2008). Все ли российские народы верно посчитали? // Демоскоп Weekly, 319 - 320. URL: http://www.demoscope.ru/weekly/2008/0319/tema01.php (дата обращения 13.12.2016).

Богоявленский Д.Д. (2012). Перепись 2010: этнический срез // Демоскоп Weekly, 531 532. URL: http://www.demoscope.ru/weekly/2012/0531/tema03.php (дата обращения 13.12.2016).

Богоявленский Д.Д. (2014). Этническая дифференциация рождаемости в России // Население России 2012: двадцатый ежегодный демографический доклад / Отв. ред. А.Г. Вишневский. М.: Изд. дом Высшей школы экономики: 174-188.

Дагестанстат (2015). Дагестан - 2015: статистический сборник. Махачкала: Дагестанстат. 
Казенин К.И. (2015а). Регулирование земельных отношений в Дагестане: социальноэкономические корни "традиционализации" // Экономическая политика. 3: 113-133.

Казенин К.И. (2015b). Земельная реформа в Дагестане: социально-политические риски // Экономические развитие России. 6: 34-39.

Казенин К.И., В.А. Козлов (2016). Омоложение материнства в Дагестане: тенденция или артефакт? // Демографическое обозрение. 3(3): 100-123.

Мудуев Ш.С. (2003). Население и хозяйство Дагестана на рубеже веков. Махачкала: Дагкнигоиздат. 304 с.

Dyson T., M. Moore (1983). On kinship structure, female autonomy, and demographic behavior in India // Population and development review. 9(1): 35-60.

Kazenin K., V. Kozlov (2016). Islam and fertility in the end of the first demographic transition: the case of North Caucasus / Paper presented at European population conference-2016. Mainz, September 1-3. 


\title{
ESTIMATING NUMBER OF CHILDREN IN VILLAGES OF DAGHESTAN: A COMPARISON OF DATA SOURCES
}

\author{
KONSTANTIN KAZENIN
}

\begin{abstract}
The paper deals with different 'local' sources of data on the number of children and fertility in the Republic of Dagestan (North Caucasus, Russia). A study of 'local' sources on fertility in comparison with census data in Dagestan is necessary for two reasons. First, the region is known to have serious problems with official demographic statistics, so that all alternative sources should be considered. Second, different parts of Dagestan demonstrate outstanding diversity with respect to fertility, which needs to be studied and explained. The paper discusses the results of a field study undertaken in Dagestan in 2015. In the course of that study, data on the number of children born in different years between 2000 and 2014 were collected from local administrations, medical institutions and schools in ten villages of Dagestan. The data of the three sources never fully agreed with each other or with census data, but showed regular, statistically significant correspondences. We hypothesize about possible reasons for the differences between the data of the sources on the basis of our interviews with local officials in the villages under study. We argue that the data of medical institutions and schools should be the most reliable. We also compare data of local administrations and medical institutions on the number of women of different age groups and study the possibility of using these data for calculating fertility rates (crude birth rate, total fertility rate, etc.) for different parts of Dagestan, in order to establish the differences between their fertility dynamics.
\end{abstract}

Key words: fertility, North Caucasus, local statistical data, crude birth rate, total fertility rate.

Konstantin I. KaZenin (kz@ranepa.ru), The Russian Presidential ACAdEMy of National Economy and PubliC ADMINISTRATION, RUSSIA.

DATE RECEIVED: SEPTEMBER 2016.

\section{REFERENCES}

Alieva V.F. (2007). Demograficheskie protsessy v sovremennom Dagestane [Demographic processes in today's Daghestan]. Moscow: Nauka. 325 p.

Andreev E.M. (2012). O tochnosti rezul'tatov rossiyskikh perepisey naseleniya i stepeni doveriya $\mathrm{k}$ raznym istochnikam informatsii [On correctness of Russian censuses and reliability of different information sources] // Voprosy statistiki [Problems in statistics]. 11:21-35.

Bogoyavlensky D.D. (2008). Vse li rossiyskie narody verno poschitali? [Were all Russian ethnic groups registered correctly?] // Demoscope Weekly. 319 - 320. URL:

http://www.demoscope.ru/weekly/2008/0319/tema01.php (accessed 13.12.2016).

Bogoyavlensky D.D. (2012). Perepis' 2010: etnicheskiy srez [2010 Census: ethnic aspect] // Demoscope Weekly, 531 - 532. URL:

http://www.demoscope.ru/weekly/2012/0531/tema03.php (accessed 13.12.2016).

Bogoyavlensky D.D. (2014). Etnicheskaya differentsiatsiya rozhdaemosti v Rossii [Ethnic differentiation of fertility in Russia] // Naselenie Rossii 2012: dvadtsatyy ezhegodnyy demograficheskiy doklad [Population of Russia: twentieth annual demographic report] / A.G. Vishnevsky, ed. Moskva: Izd. dom Vysshey shkoly ekonomiki: 174-188.

Dagestanstat [Daghestanstat] (2015). Dagestan - 2015: statisticheskiy sbornik [Daghestan-2015: Statistical sample]. Makhachkala.

Dyson T., M. Moore (1983). On kinship structure, female autonomy, and demographic behavior in India // Population and development review. 9(1): 35-60. 
Kazenin K.I. (2015a). Regulirovaniye zemel'nykh otnosheniy v Dagestane: sotsial'noekonomicheskiye korni "traditsionalizatsii"[Regulation of land relations in Dagestan: socioeconomic roots of "traditionalization"]// Ekonomicheskaya politika [Economic policy]. 3: $113-133$

Kazenin K.I. (2015b). Zemel'naya reforma v Dagestane: sotsial'no-politicheskie riski [Land reform in Daghestan: social and political risks] // Ekonomicheskoe razvitie Rossii [Economic development of Russia]. 6: 34-39.

Kazenin K., V. Kozlov (2016a). Islam and fertility in the end of the first demographic transition: the case of North Caucasus / Paper presented at European population conference-2016. Mainz, September 1-3.

Kazenin K.I., V.A. Kozlov (2016b). Omolozhenie materinstva v Dagestane: tendentsiya ili artefakt? [Young mother's age in Daghestan: real tendency or artefact of statistics] // Demograficheskoe obozrenie [Demographic review]. 3(3): 100-123.

Muduev Sh.S. (2003). Naselenie i khozyaystvo Dagestana na rubezhe vekov [Population and economy of Daghestan at the break of the centuries]. Makhachkala: Dagknigoizdat. 304 p. 